\title{
REDESAIN RAKEL DAN PEMBERIAN PEREGANGAN AKTIF MENURUNKAN BEBAN KERJA DAN KELUHAN MUSKULOSKELETAL SERTA MENINGKATKAN PRODUKTIVITAS KERJA PEKERJA SABLON PADA INDUSTRI SABLON SURYA BALI DI DENPASAR
}

\author{
${ }^{1}$ Daryono, ${ }^{2}$ I Dewa Putu Sutjana, ${ }^{3}$ I Made Muliarta
}

1. Mahasiswa Program Studi Magister Ergonomi Fisiologi Kerja Universitas Udayana

2. Staff Dosen Program Studi Magister Ergonomi Fisiologi Universitas Udayana

3. Staff Dosen Program Studi Magister Ergonomi Fisiologi Universitas Udayana

yohannesdaryono@yahoo.com

\begin{abstract}
ABSTRAK
Permasalahan ergonomi di industri sablon kain tradisional berupa sikap kerja yang tidak alamiah sehingga menimbulkan keluhan muskuloskeletal pada pekerja sablon. Untuk mengatasi masalah tersebut, khususnya bagi aktivitas sablon kain dilakukan penelitian dengan redesain rakel dan pemberian peregangan aktif. Tujuan penelitian ini adalah untuk mengetahui penggunaan redesain rakel dan pemberian peregangan aktif pada pekerja sablon kain terhadap penurunan beban kerja, keluhan muskuloskeletal dan peningkatan produktivitas kerja. Rancangan penelitian ini adalah rancangan sama subjek dengan melibatkan 12 orang pekerja sablon laki-laki, umur 2045 tahun, pengalaman kerja antara 1-5 tahun.

Penelitian menjadi dua tahap. Tahap pertama (I) subjek diberi perlakuan kerja dengan rakel tanpa redesain dan tanpa pemberian peregangan aktif. Tahap kedua (II) subjek diberi perlakuan kerja dengan redesain rakel dan pemberian peregangan aktif. Diantara kedua tahap penelitian tersebut, diberikan wash out period selama 2 hari dan adaptasi redesain rakel selama 4 hari, untuk menghilangkan carry over effects. Beban kerja diukur dari denyut nadi dengan metode 10 denyut, keluhan muskuloskeletal diukur dengan kuesioner Nordic Body Map pada 4 skala likert dan produktivitas kerja berdasarkan perbandingan antara output dan input. Data dianalisis dengan uji ShapiroWilk untuk mengetahui normalitas data, uji t-paired untuk menguji perbedaan kemaknaan variabel beban kerja dan produktivitas kerja pada tingkat kemaknaan $\alpha=0,05$ serta uji Wilcoxon untuk variabel keluhan muskuloskeletal.

Dari hasil penelitian menunjukkan bahwa redesain rakel dan pemberian peregangan aktif dapat menurunkan beban kerja sebesar 30,3\% (p<0,05) dan menurunkan keluhan muskuloskeletal sebesar 16,9\% $(\mathrm{p}<0,05)$ serta meningkatkan produktivitas kerja sebesar 45,5\% $(\mathrm{p}<0,05)$. Sehingga dapat disimpulkan bahwa redesain rakel dan pemberian peregangan aktif dapat menurunkan beban kerja dan keluhan muskuloskeletal serta meningkatkan produktivitas kerja bagi pekerja sablon. Disarankan kepada pemilik industri usaha sejenis agar melakukan perbaikan kondisi kerja yang mengacu pada prinsip ergonomi, sehingga tercipta kondisi kerja yang lebih aman, nyaman, sehat dan produktif bagi pekerja.
\end{abstract}

Kata kunci: Redesain Rakel, Peregangan Aktif, Beban Kerja, Keluhan Muskuloskeletal, Produktivitas Kerja 


\title{
REDESIGN OF RAKEL AND GIVING ACTIVE STRETCHING DECREASE WORKLOAD AND MUSCULOSKELETAL COMPLAINTS AND INCREASE WORK PRODUCTIVITY FOR PRINTING WORKER ON PRINTING INDUSTRY SURYA BALI IN DENPASAR
}

\begin{abstract}
Problems ergonomics in industrial screen printing traditional fabrics such as work attitude unnatural causing musculoskeletal disorders in workers printing. To overcome these problems, especially for fabric printing activity done by redesigning Rakel research and giving active stretching. The purpose of this study was to know the effects of the using redesigning Rakel and active stretching for the fabric screen printing workers to decrease the workload, musculoskeletal disorders and increased work productivity. The study design is the design of the same subject, involving 12 workers printing male, 20-45 years old, between 1-5 years of work experience.

Research into two phases. The first phase (I) subjects treated with Rakel without redesigning work and without giving active stretching. The second phase (II) subjects treated with redesigning work Rakel and giving active stretching. Among the two phases of the study, given a wash out period for 2 days and adaptation redesigning Rakel for 4 days, to eliminate carry-over effects. The workload is measured by the method of pulse 10 beats, musculoskeletal complaints measured by a questionnaire Nordic Body Map at 4 Likert scale and work productivity based on the ratio between output and input. Data were analyzed with the Shapiro-Wilk test to determine the normality of the data, paired t-test to test the significance difference variable workload and productivity of work at the significance level $\alpha=0.05$ and Wilcoxon test for variables musculoskeletal complaints.

The results showed that redesigning Rakel and provision of active stretching can reduce the workload of $30,3 \%(\mathrm{p}<0.05)$ and lower musculoskeletal complaints by $16,9 \%(\mathrm{p}<0.05)$ as well as increasing work productivity by $45,5 \%(\mathrm{p}<0.05)$. It concluded that the redesign Rakel and provision of active stretching can reduce the workload and musculoskeletal disorders and increase productivity for workers printing. Suggested to the owner of a similar business industry to make good working conditions referring to ergonomic principles, so as to create safer working conditions, comfortable, healthy and productive workers.
\end{abstract}

Key words: Redesign Rakel, Active Stretching, Workload Complaints, Work Productivity

\section{PENDAHULUAN}

Dunia industri di Indonesia masih didominan dengan penggunaan tenaga manusia dalam proses produksinya, terutama pada kegiatan Manual Material Handling (MMH). Aktivitas MMH mempunyai peranan vital dalam pekerjaan yang dilakukan di bagian proses produksi. Kelebihan MMH bila dibandingkan dengan penanganan material yang menggunakan alat bantu adalah fleksibilitas gerakan yang dapat dilakukan untuk beban-beban ringan.

Menurut Candra (2006), sikap kerja dengan fleksibilitas gerakan yang dipaksakan dan dilakukan secara berulang-ulang dalam kurun waktu yang lama akan dapat menyebabkan keluhan atau nyeri seperti Low Back Pain (LBP) 
(The Indonesian Journal of Ergonomic)

atau nyeri punggung bawah maupun keluhan otot yang lainnya (Muskuloskeletal disorders). Muskuloskeletal Disorders (MSDs) merupakan gangguan fungsi otot, tendon, saraf, pembuluh darah, tulang dan ligamen, akibat ketegangan atau perubahan struktur sistem muskuloskeletal dalam waktu pendek ataupun lama.

Hasil produksi dari industri kecil sangat bergantung dengan kemampuan dari pekerja di samping peralatan sederhana yang mendukung proses produksi tersebut. Para pekerja dituntut untuk bekerja dengan peralatan yang ada sehingga pekerja berusaha mengadaptasi peralatan tersebut dalam melakukan kerjanya dan terkadang pekerja bekerja melampaui kemampuan fisik yang ada dan akan timbul ketegangan otot dan keluhan yang berkaitan dengan nyeri.

Sikap kerja yang salah dan dalam durasi yang panjang akan mengakibatkan berbagai macam gangguan kesehatan yang dapat berakibat fatal. Berat beban yang diangkat para pekerja juga sangat berisiko untuk menimbulkan keluhan atau cedera, terutama cedera pada sistem muskuloskeletal para pekerja.

Industri sablon kain merupakan salah satu industri kecil yang banyak menggunakan tenaga manusia. Proses kerja pada pekerjaan sablon kain meliputi proses penyablonan, pencucian, pengeringan dan pengemasan dengan posisi kerja yang tidak ergonomis. Kondisi tersebut sangat berisiko terjadinya gangguan muskuloskleletal. Salah satu industri kecil sablon kain dengan alat tradisional dapat ditemukan di daerah Denpasar. Penyablonan kain pada industri tersebut dilakukan pada kain sepanjang minimal 30 meter atau tergantung pemesanan. Pekerjaan dilakukan oleh 2 orang dengan posisi pekerja berdiri berhadapan dekat dengan meja sablon yang panjang dan melakukan gerakan tangan mendorong alat sablon yang telah berisi bahan pewarna ke arah pekerja yang lain dan pekerja yang lain melakukan hal yang sama. Posisi pekerja membungkuk karena meja sablon memiliki lebar kurang lebih $160 \mathrm{~cm}$, dan tangan pekerja yang mendorong alat sablon harus mencapai setengah dari lebar meja $(80 \mathrm{~cm})$ saat melakukan sablon yang nantinya akan diteruskan oleh pekerja di depannya secara estafet atau bergantian. Hal tersebut dilakukan berulang sampai kain panjang tersebut terisi warna semua. Posisi yang membungkuk dan dilakukan berulang-ulang akan berisiko terjadinya keluhan pada punggung maupun bahu pekerja. Alat untuk meratakan warna pada sablon terbuat dari kayu pipih, sehingga pekerja harus memegang kayu dengan cara menjepit pada telapak tangan dengan jepitan pada ibu jari melawan keempat jari lainnya. Hal ini akan dapat menimbulkan keluhan otot terutama pada tangan, beberapa karyawan terutama pada bagian cetak sablon mengeluhkan adanya nyeri terutama pada area sekitar ibu jari tangan dan pergelangan tangan. Gerakan tangan dan pergelangan tangan secara berulang saat bekerja akan dapat menyebabkan beberapa kasus penyakit, salah satunya adalah De Quervain Syndrome (Waldman, 2012).

Setelah selesai disablon, kain dikeringkan di atas meja sablon dan meja sablon diberi kain yang lain untuk dilakukan penyablonan. Setelah selesai dilakukan pengepresan untuk memperkuat warna pada kain sehingga tidak mengelupas dan dilanjutkan dengan pencucian di bak pencucian, kemudian ditiriskan dan akhirnya dijemur di bawah terik matahari.

Sikap kerja yang tidak alami atau tidak ergonomis antara lain punggung terlalu membungkuk, pergerakan tangan terangkat dan sebagainya. Semakin jauh posisi tubuh dari pusat gravitasi tubuh, maka semakin tinggi pula risiko 
(The Indonesian Journal of Ergonomic)

terjadinya keluhan muskuloskeletal. Dari observasi lapangan, umumnya pekerja berada dalam postur yang berisiko seperti membungkuk dan menunduk dan postur tidak alamiah lainnya, hal tersebut terjadi karena peralatan yang kurang memadai sehingga diperlukan desain ulang pada stasiun kerja bagi para pekerja sablon untuk mengurangi beban kerja yang dialami pekerja sablon kain manual. Berdasarkan penelitian Arimbawa (2009), redesain peralatan kerja pembuatan minyak kelapa secara ergonomis dapat menurunkan beban kerja dari kategori pekerjaan sedang menjadi ringan yang ditunjukkan dengan terjadinya penurunan rerata denyut nadi kerja sebesar 16,57 denyut/menit atau sebesar $14,69 \%$ dan keluhan muskuloskeletal mengalami penurunan sebesar 14,94.

Upaya pencegahan untuk mengurangi tingkat keluhan nyeri punggung bawah pada pekerja dalam melakukan pekerjaan dapat dilakukan melalui aplikasi ergonomi yang salah satunya adalah dengan pemberian latihan peregangan otot. Diperlukan kesiapan dari tubuh pekerja ketika akan memulai pekerjaan sehingga diharapkan dapat memperkecil atau bahkan menghilangkan keluhan muskuloskeletal.

Salah satu bentuk persiapan tubuh sebelum bekerja adalah dengan melakukan peregangan atau stretching yang dapat dilakukan sendiri atau disebut Active Stretching dengan bentuk-bentuk latihan peregangan yang sederhana. Peregangan adalah aktivitas fisik yang paling sederhana dan merupakan penyeimbang sempurna untuk keadaan diam dan tidak aktif bergerak dalam waktu lama. Peregangan teratur di sela pekerjaan akan mengurangi ketegangan otot, memperbaiki peredaran darah, mengurangi kecemasan, perasaan tertekan, kelelahan, membuat pekerja merasa lebih baik (Anderson, 2010). $\begin{array}{ccc}\text { Menurut } & \text { Okananto } & (2014) \text {, } \\ \text { terjadi penurunan } \quad 40,93 \% & \text { tingkat }\end{array}$ keluhan nyeri pinggang dan punggung bawah (low back pain) setelah diberikan perlakuan peregangan (stretching) pada pekerja bagian menjahit pada salah satu rumah produksi di Semarang. Hal ini sejalan dengan penelitian Permana (2010) dalam penelitiannya yang dikakukan pekerja wanita pengepak jamu, menunjukkan perbedaan yang signifikan antara nilai kesegaran punggung responden sebelum dan sesudah diberi latihan peregangan selama lima hari berturut-turut dengan rincian dua kali perlakuan setiap harinya (pagi dan sore hari). Permana menyarankan agar melakukan stretching sebelum dan setelah bekerja untuk mengurangi keluhan muskuloskeletal.

Peregangan pada otot-otot pada para pekerja akan membuat tubuh siap dalam melakukan kegiatan serta dapat mengurangi dampak cedera yang sangat rentan, meningkatkan fleksibilitas atau kelenturan 48,01\% dan mampu meningkatkan produktivitas sebesar 48,84\% (Arsil, 2012).

\section{METODE PENELITIAN}

\section{Rancangan Penelitian}

Penelitian eksperimental ini menggunakan rancangan sama subjek (treatment by subject design). Diperlukan periode wash out untuk menghilangkan efek respon sisa (residual effect).

Tujuan penelitian ini untuk mengetahui dan membuktikan penggunaan redesain rakel dan pemberian peregangan aktif pada pekerja sablon kain terhadap penurunan beban kerja, keluhan muskuloskeletal dan peningkatan produktivitas kerja. 
(The Indonesian Journal of Ergonomic)

\section{Populasi dan Sampel}

Populasi penelitian secara random adalah 12 orang pekerja lakilaki sablon pada industri kecil sablon kain di Denpasar Selatan. Umur subjek penelitian adalah berkisar antara 20-45 tahun dengan tingkat pendidikan antara SD sampai dengan SMA. Pengalaman kerja sebagai pekerja sablon yang merupakan indikator yang menunjukkan keterampilan antara 1-5 tahun.

Teknik penentuan sampel menggunakan random sampling sederhana. Dari jumlah populasi yang ada dipilih calon sampel yang memenuhi kriteria inklusi. Jumlah sampel yang dibutuhkan adalah 12 orang.

\section{Instrumen Penelitian}

Beban kerja merupakan beban yang diterima oleh pekerja baik dari dalam maupun dari luar tubuh pekerja selama melakukan pekerjaannya yang dihitung berdasarkan rerata peningkatan denyut nadi, diukur setiap periode dengan menggunakan metode 10 denyut pada arteri radialis pergelangan tangan kiri dalam posisi berdiri.

Keluhan muskuloskeletal pada subjek diukur dengan menggunakan kuesioner Nordic Body Map. Pengukuran tersebut bersifat subjektif. Sebelum dan sesudah memulai pekerjaan pada masingmasing periode, seluruh subjek mengisi kuesioner Nordic Body Map.

Produktivitas kerja dihitung berdasarkan rumus sebagai berikut:

Produktivitas Kerja $=\frac{\text { Output }(O)}{\text { Input }(I) \times \text { Time }(T)}$

Indikator produktivitas kerja, adalah:

1. Luaran (Output) adalah rerata jumlah kain yang dapat disablon per satuan waktu untuk masingmasing kelompok pekerja sablon.
2. Masukan (Input) adalah tenaga yang dikeluarkan selama melakukan pekerjaan cetak sablon pada kain dengan menggunakan redesain alat yang didasarkan pada rerata nadi kerja kelompok pekerja sablon (denyut/menit).

3. Waktu (Time) adalah waktu yang diperlukan untuk menyelesaikan pekerjaan cetak sablon pada kain.

Hasil pada penelitian ini diolah menggunakan komputer program SPSS.

\section{HASIL PENELITIAN}

\section{Data Karakteristik Subjek Penelitian}

Deskripsi karakteristik subjek penelitian disajikan pada Tabel 1.

Tabel 1 Karakteristik Subjek Pekerja Sablon Surya Bali Denpasar $(n=12)$

\begin{tabular}{lccc}
\multicolumn{4}{c}{ Surya Bali Denpasar $(\mathrm{n}=12)$} \\
\hline $\begin{array}{c}\text { Karakteristik } \\
\text { Subjek }\end{array}$ & Rerata & $\begin{array}{c}\text { Simpang } \\
\text { Baku }\end{array}$ & Rentangan \\
\hline $\begin{array}{l}\text { Umur (tahun) } \\
\text { Lama Kerja } \\
\text { (tahun) }\end{array}$ & 28,5 & 3,8 & $21-35$ \\
\hline
\end{tabular}

Rerata umur pekerja sablon adalah $28,5 \pm 3,8$ tahun dan rerata lama kerja $3,08 \pm 0,1$ tahun. Dari segi umur, subjek termasuk dalam kategori produktif, sedangkan dari segi lamanya bekerja subjek termasuk dalam kategori berpengalaman atau cukup lama bekerja.

\section{Analisis Hasil Proses Kerja dan Sikap Kerja}

Analisis penggunaan rakel yang telah diredesain sebagai berikut:

1. Sikap kerja pekerja sablon yang membungkuk dapat dihindarkan dan diubah menjadi lebih tegak serta lingkup gerak dari sendi dapat dikurangi yang awalnya sendi bahu memiliki sudut $120^{\circ}$ menurun menjadi $70^{\circ}$ serta sudut pada punggung bawah dari $70^{\circ}$ menurun 


\section{(The Indonesian Journal of Ergonomic)}

menjadi $30^{\circ}$. Dengan penghitungan menggunakan RULA skor yang diperoleh menurun, dari skor 7 menjadi 4 (perlu dilakukan penelitian lebih lanjut tetapi perubahan stasiun kerja mungkin diperlukan).

2. Sikap kerja pekerja sablon yang biasanya menjepit rakel dapat diubah menjadi menggenggam tangkai tambahan pada rakel.

\section{Analisis Uji Normalitas Data}

Uji normalitas data menggunakan uji Shapiro-Wilk pada tingkat kemaknaan 0,05. Hasil uji Shapiro-Wilk tersebut disajikan pada Tabel 2

Tabel 2 Hasil Uji Normalitas Data dengan Uji Shapiro-Wilk $(\mathrm{n}=12)$

\begin{tabular}{lcl}
\hline \multicolumn{1}{c}{ Variabel } & $\begin{array}{c}\text { Nilai } \\
\mathrm{p}\end{array}$ & Keterangan \\
\hline $\begin{array}{l}\text { Denyut Nadi Istirahat } \\
\text { (Periode I) }\end{array}$ & 0,251 & $\begin{array}{l}\text { Berdistribusi } \\
\text { normal }\end{array}$ \\
\hline $\begin{array}{l}\text { Denyut Nadi Istirahat } \\
\text { (Periode II) }\end{array}$ & 0,201 & $\begin{array}{l}\text { Berdistribusi } \\
\text { normal }\end{array}$ \\
\hline $\begin{array}{l}\text { Denyut Nadi Kerja } \\
\text { (Periode I) }\end{array}$ & 0,041 & $\begin{array}{l}\text { Tidak } \\
\text { berdistribusi } \\
\text { normal }\end{array}$ \\
\hline $\begin{array}{l}\text { Denyut Nadi Kerja } \\
\text { (Periode II) }\end{array}$ & 0,878 & $\begin{array}{l}\text { Berdistribusi } \\
\text { normal }\end{array}$ \\
\hline Nadi Kerja (Periode I) & 0,162 & $\begin{array}{l}\text { Berdistribusi } \\
\text { normal }\end{array}$ \\
\hline Nadi Kerja (Periode II) & 0,775 & $\begin{array}{l}\text { Berdistribusi } \\
\text { normal }\end{array}$ \\
\hline $\begin{array}{l}\text { Keluhan Muskuloskeletal } \\
\text { Sebelum Kerja (Periode I) }\end{array}$ & 0,031 & $\begin{array}{l}\text { Tidak } \\
\text { berdistribusi } \\
\text { normal }\end{array}$ \\
\hline $\begin{array}{l}\text { Keluhan Muskuloskeletal } \\
\text { Sebelum Kerja (Periode II) }\end{array}$ & 0,052 & $\begin{array}{l}\text { Berdistribusi } \\
\text { normal }\end{array}$ \\
\hline $\begin{array}{l}\text { Keluhan Muskuloskeletal } \\
\text { Sesudah Kerja (Periode I) }\end{array}$ & 0,032 & $\begin{array}{l}\text { Tidak } \\
\text { berdistribusi } \\
\text { normal }\end{array}$ \\
\hline $\begin{array}{l}\text { Keluhan Muskuloskeletal } \\
\text { Sesudah Kerja (Periode II) }\end{array}$ & 0,046 & $\begin{array}{l}\text { Tidak } \\
\text { berdistribusi } \\
\text { normal }\end{array}$ \\
\hline $\begin{array}{l}\text { Produktivitas Kerja } \\
\text { (Periode I) }\end{array}$ & 0,224 & $\begin{array}{l}\text { Berdistribusi } \\
\text { normal }\end{array}$ \\
\hline $\begin{array}{l}\text { Produktivitas Kerja } \\
\text { (Periode II) }\end{array}$ & 0,198 & $\begin{array}{l}\text { Berdistribusi } \\
\text { normal }\end{array}$ \\
\hline
\end{tabular}

Hasil uji Shapiro-Wilk semua data produktivitas kerja pada kedua Periode adalah berdistribusi normal $(\mathrm{p}>0,05)$ dan pada beban kerja hanya denyut nadi kerja Periode I yang tidak berdistribusi normal, sedangkan data keluhan muskuloskeletal adalah tidak berdistribusi normal $(\mathrm{p}<0,05)$, kecuali pada keluhan muskuloskeletal sebelum kerja pada Periode II.

\section{Analisis Beban Kerja}

Beban kerja diukur berdasarkan denyut nadi pekerja melalui selisih denyut nadi kerja dengan denyut nadi istirahat.

Tabel 3 Hasil Uji Perbedaan Denyut Nadi Istirahat, Denyut Nadi Kerja dan Nadi Kerja Periode I dan Periode II $(\mathrm{n}=12)$

\begin{tabular}{|c|c|c|c|c|c|}
\hline \multirow{2}{*}{ Variabel } & $\begin{array}{c}\text { Periode } \\
\text { I }\end{array}$ & $\begin{array}{c}\text { Periode } \\
\text { II }\end{array}$ & \multirow{2}{*}{$\begin{array}{c}\text { Nilai } \\
\mathrm{t}\end{array}$} & \multirow{2}{*}{$\begin{array}{c}\text { Nilai } \\
\text { p }\end{array}$} & \multirow{2}{*}{ Keterangan } \\
\hline & $\begin{array}{l}\text { Rerata } \\
\pm \text { SB }\end{array}$ & $\begin{array}{c}\text { Rerata } \\
\pm \mathrm{SB} \\
\end{array}$ & & & \\
\hline $\begin{array}{l}\text { Denyut } \\
\text { Nadi } \\
\text { Istirahat } \\
(\mathrm{dpm}) \\
\end{array}$ & $\begin{array}{c}79,28 \pm \\
3,36\end{array}$ & $\begin{array}{c}30,06 \pm \\
3,02\end{array}$ & $-3,02$ & 0,012 & $\begin{array}{c}\text { Berbeda } \\
\text { bermakna }\end{array}$ \\
\hline $\begin{array}{l}\text { Denyut } \\
\text { Nadi } \\
\text { Kerja } \\
\text { (dpm) }\end{array}$ & $\begin{array}{c}113,00 \pm \\
6,18\end{array}$ & $\begin{array}{l}103,55 \\
\pm 7,04\end{array}$ & 8,36 & 0,0001 & $\begin{array}{c}\text { Berbeda } \\
\text { bermakna }\end{array}$ \\
\hline $\begin{array}{l}\text { Nadi } \\
\text { Kerja } \\
(\text { dpm })\end{array}$ & $\begin{array}{c}33,72 \pm \\
4,55\end{array}$ & $23,50 \pm$ & 9,16 & 0,0001 & $\begin{array}{c}\text { Berbeda } \\
\text { bermakna }\end{array}$ \\
\hline
\end{tabular}

Hasil uji t-paired, Periode I dan Periode II menghasilkan penurunan nadi kerja berbeda secara bermakna $(\mathrm{p}<0,05)$. Rerata nadi kerja mengalami penurunan sekitar 30,3\% setelah dilakukan perlakuan dibandingkan tanpa dilakukan perlakuan.

\section{Analisis Keluhan Muskuloskeletal}

Data keluhan muskuloskeletal pekerja sablon tidak berdistribusi normal, sehingga untuk menganalisis perbedaan efek perlakuan digunakan uji Wilcoxon pada tingkat kepercayaan $\alpha=0,05$.

Tabel 4 Hasil Uji Perbedaan Skor Keluhan Muskuloskeletal Sebelum dan Sesudah Perlakuan pada Periode I dan Periode II $(n=12)$

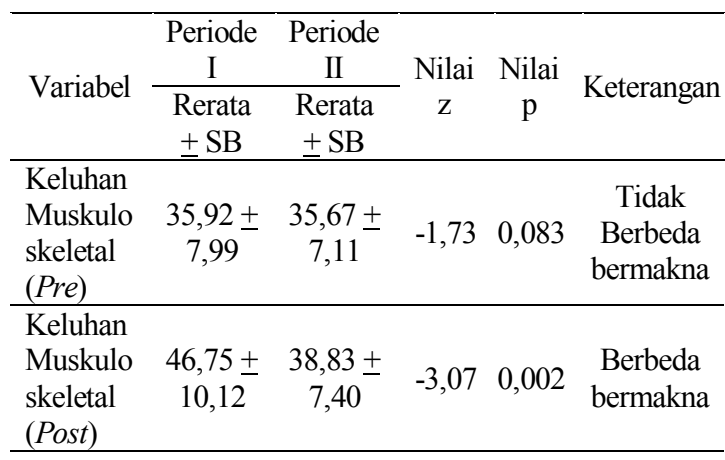




\section{(The Indonesian Journal of Ergonomic)}

Uji beda data sesudah perlakuan antar kelompok mendapatkan hasil nilai $p$ pada keluhan muskuloskeletal lebih kecil dari 0,05 sehingga Ho ditolak, yang berarti terdapat perbedaan yang signifikan pada keluhan muskuloskeletal pekerja sablon Periode dibandingkan pada Periode II. Keluhan muskuloskeletal mengalami penurunan sekitar $16,9 \%$ setelah dilakukan perlakuan berupa redesain rakel dan pemberian peregangan aktif pada para pekerja sablon kain (Periode II).

\section{Analisis Produktivitas Kerja}

Luaran (output) adalah rerata jumlah kain yang dapat disablon oleh pekerja sablon kain (meter) per satuan waktu, sedangkan masukan (input) adalah beban yang diterima pekerja sablon kain berupa nadi kerja dan waktu (time) adalah waktu yang diperlukan untuk menyelesaikan pekerjaan sablon kain (180 menit). Produktivitas kerja adalah perbandingan antara luaran (output) dan masukan (input) per satuan waktu.

\begin{tabular}{|c|c|c|c|c|c|}
\hline \multirow{2}{*}{ Variabel } & $\begin{array}{c}\text { Periode } \\
\text { I }\end{array}$ & $\begin{array}{c}\text { Periode } \\
\text { II }\end{array}$ & \multirow{2}{*}{$\begin{array}{c}\text { Nilai } \\
\mathrm{t}\end{array}$} & \multirow{2}{*}{$\begin{array}{l}\text { Nilai } \\
\mathrm{p}\end{array}$} & \multirow{2}{*}{ Keterangan } \\
\hline & $\begin{array}{c}\text { Rerata } \\
\pm \text { SB } \\
\end{array}$ & $\begin{array}{l}\text { Rerata } \\
\pm \text { SB } \\
\end{array}$ & & & \\
\hline $\begin{array}{l}\text { Produk- } \\
\text { tivitas } \\
\text { Kerja }\end{array}$ & $\begin{array}{c}0,11 \pm \\
0,02\end{array}$ & $\begin{array}{c}0,16 \pm \\
0,04\end{array}$ & $-6,45$ & 0,0001 & $\begin{array}{c}\text { Berbeda } \\
\text { bermakna }\end{array}$ \\
\hline
\end{tabular}

Berdasarkan hasil uji t-paired diketahui bahwa rerata produktivitas kerja antara periode I dan dengan periode II berbeda bermakna $(p<0,05)$, sehingga Ho ditolak, yang berarti produktivitas tanpa redesain rakel dan pemberian peregangan aktif tidak sama dibandingkan produktivitas dengan redesain rakel dan pemberian peregangan aktif. Disimpulkan bahwa produktivitas kerja meningkat sebesar 45,5\% setelah dilakukan perlakuan berupa redesain rakel dan pemberian peregangan aktif pada pekerja sablon.

\section{PEMBAHASAN}

\section{Karakteristik Subjek Penelitian}

Rerata umur karyawan yang menjadi subjek dalam penelitian ini adalah 28,5 tahun dengan rentang usia antara 21-35 tahun atau dalam usia produktif. Rerata lama kerja karyawan yang menjadi subjek dalam penelitian ini adalah 3,08 tahun dengan rentang lama bekerja antara 2-5 tahun.

Jenis pekerjaan pada industri kecil sablon kain adalah bersifat kerja fisik dengan menggunakan manual handling dan berdurasi kerja 7 jam kerja serta 1 jam untuk waktu beristirahat. Dengan rentang usia pekerja sablon yang masih produktif tersebut, pekerja masih dapat bekerja dengan optimal, akan tetapi tubuh akan mengalami keluhan apabila melakukan kerja secara terus menerus dengan kondisi otot bekerja secara berlebihan, baik terulur maupun menahan beban. Pengalaman kerja yang berkisar 2-5 tahun cukup dapat mempengaruhi kondisi tubuh berupa keluhan pada muskuloskeletal maupun beban kerja dari para pekerja.

Hasil analisis yang diperoleh sesuai dengan Kantana (2010), yang menyebutkan bahwa pada umumnya keluhan muskuloskeletal mulai dirasakan pada usia kerja yaitu 25-65 tahun. Semakin lama pekerja bekerja atau semakin lama pekerja terpapar faktor risiko, maka semakin besar pula risiko kemungkinan mengalami keluhan muskuloskeletal dan dapat menambah beban kerja dari pekerja, sehingga akan mempengaruhi produktivitas kerja dari pekerja tersebut. 
(The Indonesian Journal of Ergonomic)

\section{Hasil Proses Kerja dan Sikap kerja \\ Berdasarkan hasil analisis}

RULA pada pekerja dengan perlakuan berupa redesain kerja, nilai skor pada RULA mengalami penurunan. Skor awal RULA tanpa perlakuan adalah 7 (perlu dilakukan investigasi dan segera dilakukan perbaikan atau perubahan pada stasiun kerja) menurun setelah dilakukan perlakuan dengan skor RULA adalah 4 (perlu dilakukan penelitian atau investigasi lebih lanjut tetapi perubahan stasiun kerja mungkin diperlukan).

Hasil analisis dengan mengurangi posisi kerja pekerja sablon yang terlalu membungkuk akan dapat mengurangi keluhan muskuloskeletal. Posisi membungkuk menyebabkan otot lebih tegang, sehingga pekerja akan membutuhkan ketahanan otot yang besar, keadaan ini akan menyebabkan pembebanan dan peregangan otot yang berlebihan yang dapat menyebabkan keluhan muskuloskeletal dan meningkatkan beban kerja dari pekerja.

Hasil analisis lain pada sikap kerja adalah posisi menjepit pada rakel diubah menjadi posisi menggenggam. Menurut Waldman (2012), posisi menjepit yang dilakukan secara berulang pada saat melakukan pekerjaan besar kemungkinan dapat menimbulkan keluhan pada tangan (De Quervain Syndrome). Diharapkan posisi kerja dengan tangan dalam keadaan menggenggam akan dapat mencegah terjadinya kasus de quervain syndrome pada tangan.

\section{Beban Kerja}

Berdasarkan analisis uji perbedaan efek, denyut nadi kerja pekerja sablon kain sebelum perlakuan $(113+6,18)$ dan sesudah perlakuan $(103,55+7,04)$ termasuk dalam kategori beban kerja berskala sedang (100-125 dpm). Hasil penelitian menunjukkan bahwa rerata beban kerja pada pekerja sablon kain sebelum dilakukan perlakuan adalah $33,72+4,55 \mathrm{dpm}$, sedangkan rerata beban kerja pada pekerja sablon kain setelah dilakukan perlakuan berupa redesain rakel dan pemberian peregangan aktif adalah $23,5 \pm 5,03 \mathrm{dpm}$ sehingga terjadi penurunan beban kerja sebesar 30,3\% dan berbeda secara bermakna $(\mathrm{p}<0,05)$.

Denyut nadi istirahat berbeda bermakna dengan intepretasi bahwa terdapat beberapa faktor yang mempengaruhi denyut nadi istirahat subjek sebelum dilakukan pengukuran antara lain faktor kegiatan fisik yang dilakukan subjek sebelum datang ke tempat kerja, faktor psikis atau emosi dan faktor kurangnya subjek beristirahat. Oleh karena adanya perbedaan, maka yang dianalisis adalah selisihnya atau nadi kerja.

Hasil penelitian mengenai redesain stasiun kerja sejalan dengan penelitian Sutarna (2011), yang menyatakan bahwa redesain stasiun kerja berupa penambahan alat kedudukan pelat eser dapat menurunkan beban kerja sebesar 10,4\%, hasil analisis menunjukkan bahwa sebelum menggunakan alat kedudukan pelat eser (P0) rerata beban kerja mahasiswa sebesar 104,4 denyut per menit sedangkan setelah menggunakan alat kedudukan pelat eser (P1) sebesar 93,5 denyut permenit. Hal ini juga bisa dikatakan bahwa terjadi peningkatan kinerja mahasiswa ditinjau dari penurunan beban kerja.

Menurunnya beban kerja disebabkan oleh karena redesain pada rakel menyebabkan berkurangnya posisi atau postur membungkuk pada pekerja sablon saat melakukan kerja secara manual handling, disamping tubuh dari pekerja telah dipersiapkan untuk melakukan aktivitas kerja karena terlebih dahulu melakukan peregangan aktif (active stretching) secara teratur. 
(The Indonesian Journal of Ergonomic)

Hasil penelitian mengenai
peregangan aktif sejalan dengan penelitian Setiawan (2014) pada buruh yang bekerja dengan melakukan gerakan yang dapat memberikan beban pada tubuh bagian atas terutama pada otot-otot anggota gerak atas yaitu otot lengan, bahu dan leher. Salah satu gerakan tersebut adalah peregangan aktif yang dapat memberikan manfaat untuk mengembalikan kepekaan kerja saraf sensorik-motorik, mengurangi rasa lelah, mengurangi kemungkinan kesalahan kerja, mengembalikan (recovery) tingkat kesegaran awal seperti sebelum mulai kerja dan mencegah terjadinya kelainan postur akibat posisi kerja yang dipertahankan dalam waktu lama. Uji coba subjek penelitian selama 2 minggu pada kelompok perlakuan menunjukkan respon yang positif dan hasil denyut nadi yang cenderung menurun, sehingga beban kerja dapat menurun.

Hasil penelitian ini sesuai dengan teori yang dikemukakan oleh Anderson (2010) yang menyebutkan peregangan aktif dapat mengurangi ketegangan otot dan memperbaiki peredaran darah, sehingga tubuh akan lebih siap dalam bekerja. Pendapat ini sesuai pula dengan teori yang dikemukakan oleh Kroemer (2008) dengan adanya perbaikan peredaran darah, oksigen akan ditransportasikan ke otot-otot oleh darah. Apabila oksigen cukup maka sistem aerobik akan berlangsung, karena metabolisme lengkap dan hasil akhir energi lebih banyak sehingga kebutuhan oksigen terpenuhi dan denyut nadi tidak bekerja lebih cepat.

\section{Keluhan Muskuloskeletal}

Terdapat perbedaan pada hasil pengisian lembar Nordic Body Map sebelum dan sesudah melakukan kerja pada kedua periode. Hasil penelitian menunjukkan bahwa rerata keluhan muskuloskeletal pada pekerja sablon kain sebelum dilakukan perlakuan adalah $46,75 \pm 10,12$, sedangkan rerata keluhan muskuloskeletal pada pekerja sablon kain setelah dilakukan perlakuan berupa redesain rakel dan pemberian peregangan aktif adalah $38,83 \pm 7,40$. Terjadi penurunan keluhan subjektif sebesar $16,9 \%$ dan berbeda secara bermakna $(p<0,05)$.

Keluhan muskuloskeletal terjadi pada otot-otot yang dipakai dalam melakukan kerja sablon dengan gerakan otot yang berulang, yaitu pada bagian bahu dan punggung bawah. Keluhan muskuloskeletal tersebut disebabkan adanya kontraksi otot yang mengakibatkan peningkatan tekanan dalam otot sehingga terjadi obstruksi aliran darah dalam pembuluh darah. Berkurangnya aliran darah berpotensi menyebabkan terjadinya kontraksi statis. Dengan pengerahan tenaga otot yang tinggi dapat dimungkinkan terjadi pemecahan pada internal sel otot. Selain itu, akumulasi dari ion kalsium dapat menyebabkan kerusakan sel. Diasumsikan bahwa kontraksi statis yang berlangsung lama dapat memicu terjadinya proses patologis yang menyebabkan keluhan nyeri. Hal ini sesuai dengan teori kelebihan gerak yang menjelaskan bahwa gerak membutuhkan usaha fisik dan jika berlebihan akan melewati batas atau komponen sistem.

Terjadinya penurunan keluhan muskuloskeletal disebabkan sikap kerja pekerja sablon mengalami perbaikan karena penggunaan redesain pada rakel. Otot-otot bekerja tidak secara berlebihan pada saat melakukan kerja dikarenakan lingkup gerak sendi saat melakukan kerja menurun terutama pada bagian sendi bahu dan pinggang. Hal ini didukung pula dengan dilakukannya penguluran aktif yang akan membangun kelenturan otot secara 
(The Indonesian Journal of Ergonomic)

aktif sebelum melakukan kerja sehingga otot lebih siap dalam melakukan pekerjaan serta dapat menghindari terjadinya keluhan muskuloskeletal.

Hasil penelitian mengenai redesain pada stasiun kerja sejalan dengan penelitian Haryawan (2015), yang menyatakan redesain stasiun kerja dengan mengubah tangkai pegangan roller cat dapat menurunkan keluhan muskuloskeletal sebesar $37,1 \%$ dan berbeda secara bermakna pada pekerja cat plafon. Dengan mengurangi sudut postur tubuh dalam bekerja dapat mengurangi pula beban muskuloskeletal saat melakukan aktivitas kerjanya.

Hasil ini sejalan dengan penelitian Susana (2016), yang menyatakan redesain stasiun kerja berupa rancangan ruang pengering ikan secara tradisional dapat menurunkan keluhan muskuloskeletal sebesar $26,7 \%$ pada perajin ikan di daerah Mataram. Saat melakukan proses pengeringan, posisi pekerja berjongkok dengan sikap kerja membungkuk dan posisi tetap berjongkok saat pekerja melakukan perpindahan tempat atau bergeser, hal ini merupakan sikap kerja yang tidak alamiah yang dapat menimbulkan keluhan pada muskuloskeletal para pekerja. Perlu dilakukan intervensi ergonomi melalui perbaikan alat kerja sehingga posisi pekerja menjadi posisi berdiri.

Sedangkan hasil penelitian mengenai pemberian peregangan aktif pada pekerja sablon kain ini sejalan dengan penelitian dari Indrawati dkk (2015). Pemberian latihan peregangan dapat menurunkan keluhan muskuloskeletal secara bermakna. Penurunan keluhan muskuloskeletal yang didapat adalah sebesar $71,98 \%$ pada karyawan di bagian Rekam Medis Rumah Sakit Sanglah Denpasar.

Hasil penelitian lain yang sejalan mengenai peregangan adalah penelitian
Irwanti (2011). Peregangan otot di sela pembelajaran salah satunya dapat menurunkan keluhan muskuloskeletal, hasil yang diperoleh adalah penurunan keluhan muskuloskeletal sebesar 64,28\%. Penurun disebabkan karena pada saat diberikan peregangan aktif, otot dapat pulih kembali dan dapat membangun zatzat yang diperlukan bagi otot, dalam hal ini adalah asam laktat sisa metabolisme otot didaur ulang dan diubah menjadi karbondioksida $\left(\mathrm{CO}_{2}\right)$, air dan glikogen serta protein yang akan dimanfaatkan kembali untuk menjadi energi.

Hasil penelitian yang dilakukan Okananto (2014) mengenai peregangan pada pekerja bagian menjahit di daerah Semarang sejalan dengan penelitian ini. Hasil penelitian menyebutkan terjadi penurunan keluhan muskuloskeletal terutama pada bagian punggung bawah sebesar $\quad 40,93 \%$ setelah dilakukan perlakuan peregangan (stretching) pada kelompok perlakuan. Peregangan merupakan penyeimbang sempurna untuk keadaan pekerjaan yang dilakukan berulang-ulang dan dalam jangka waktu lama yang bermanfaat untuk mengurangi ketegangan otot, memperbaiki peredaran darah dan mengurangi risiko cedera sehingga membuat pekerjaan menjadi lebih mudah dan membuat kondisi tubuh lebih baik.

\section{Produktivitas Kerja}

Terdapat perbedaan hasil produktivitas kerja pada kedua periode. Berdasarkan hasil penelitian menunjukkan bahwa rerata produktivitas kerja sebelum dilakukan perlakuan adalah $0,11 \pm 0,02, \quad$ sedangkan rerata produktivitas kerja setelah dilakukan perlakuan berupa redesain rakel dan pemberian peregangan aktif adalah $0,17 \pm 0,04$. Terjadi peningkatan produktivitas kerja secara keseluruhan sebesar 45,5\% dan berbeda secara bermakna $(p<0,05)$. 
(The Indonesian Journal of Ergonomic)

Hasil penelitian ini sejalan dengan penelitian Sutarna (2011). Penelitian yang dilakukan pada mahasiswa tersebut menyatakan bahwa terjadi peningkatan produktivitas kerja mahasiswa sebesar $76,6 \%$ setelah dilakukan redesain stasiun kerja berupa penambahan alat kedudukan pelat eser.

Hasil penelitian mengenai produktivitas kerja setelah dilakukan redesain stasiun kerja dan pemberian active stretching ini sesuai dengan teori yang dikemukakan oleh Wignyosoebroto (2008). Disebutkan bahwa peningkatan produktivitas kerja dapat dilakukan dengan melalui dua faktor yaitu: faktor teknis (dilakukan dengan melakukan evaluasi alat kerja dan perbaikan alat kerja atau stasiun kerja, dalam penelitian ini dilakukan redesain stasiun kerja pada rakel) dan faktor non teknis (melalui perbaikan metode dan sistem kerja, team work, pengaturan waktu kerja dan hal lain yang berorientasi pada human factor, dalam penelitian ini berorientasi pada human faktor yaitu pemberian active stretching yang bertujuan mempersiapkan tubuh pekerja sablon kain dalam melakukan pekerjaannya). Jika kedua faktor tersebut dapat dipenuhi dan dilakukan secara bersamaan, maka akan dapat meningkatkan produktivitas kerja secara lebih maksimal.

\section{SIMPULAN DAN SARAN}

\section{Simpulan}

Berdasarkan hasil penelitian dan analisis data, maka penelitian ini dapat disimpulkan bahwa:

1. Redesain rakel dan pemberian peregangan aktif menurunkan beban kerja sebesar 30,3\% pada pekerja sablon kain.
2. Redesain rakel dan pemberian peregangan aktif menurunkan keluhan muskuloskeletal sebesar $16,9 \%$ pada pekerja sablon kain.

3. Redesain rakel dan pemberian peregangan aktif meningkatkan produktivitas kerja sebesar 45,5\% pada pekerja sablon kain.

\section{Saran}

Berdasarkan simpulan penelitian, disarankan beberapa hal yang berkaitan dengan penelitian di masa yang akan datang, sebagai berikut:

1. Diharapkan penggunaan redesain rakel dan pemberian peregangan aktif dapat dilakukan pada industri kecil sablon.

2. Bagi peneliti berikut agar lebih baik dalam merancang redesain rakel dengan menggunakan jumlah sampel yang lebih banyak dan tidak terbatas pada satu industri kecil.

3. Diharapkan rekan-rekan mahasiswa pasca-sarjana dapat mengadakan penelitian lebih lanjut terhadap metode redesain stasiun kerja dan penambahan metode lain untuk mendapatkan hasil yang lebih optimal dan dapat dijadikan masukan yang bermanfaat bagi kemajuan ilmu pengetahuan.

\section{DAFTAR PUSTAKA}

1. Anderson, B. 2010. Stretching in The Office. Serambi Ilmu Semesta. Jakarta

2. Arimbawa, I.M.G. 2009. Redesain Peralatan Kerja Secara Ergonomis Meningkatkan Kinerja Pembuat Minyak Kelapa Tradisional di Kecamatan Dawan Klungkung. Disertasi. Program Pascasarjana S3 Ilmu Kedokteran Universitas Udayana. 
(The Indonesian Journal of Ergonomic)

3. Arsil. 2012. Industri Informal pada Usaha Penjahit. Kesehatan Masyarakat. Fakultas Ilmu Kesehatan Universitas Islam Negeri Alauddin Makasar.

4. Chandra, B. 2006. Pengantar Kesehatan Lingkungan. EGC. Jakarta

5. Haryawan, I.G.A. 2015. Penggunaan Tangkai Pegangan Roller Cat yang Dimodifikasi Meningkatkan Kinerja Pengecat Plafon Rukan di Denpasar. Tesis. Denpasar: Universitas Udayana.

6. Indrawati, E.P., Tirtayasa, I.K., Adiatmika, I.P.G. 2015. Pelatihan Peregangan dan Istirahat Aktif Menurunkan Keluhan Muskuloskeletal, Kelelahan Mata dan Meningkatkan Konsentrasi Kerja Karyawan Rekam Medis Rumah Sakit Sanglah Denpasar. Jurnal Ergonomi Indonesia. Volume 1, No 1, 2015 [cited 2016 Mei 12]. Available from: URL: http://ojs.unud.ac.id/index.php/jei/a rticle/view/12025/8323

7. Irwanti, N. K. D. 2011. Peregangan Otot di Sela Pembelajaran Mengurangi Kebosanan, Kelelahan dan Keluhan Muskuloskeletal Peserta Didik Kelas X, SMK Pariwisata Triatma Jaya Badung. Tesis. Denpasar: Universitas Udayana.

8. Kantana, T. 2010. Faktor-Faktor Yang Mempengaruhi Keluhan Low Back Pain Pada Kegiatan Mengemudi Tim Ekspedisi PT Enseval Putera Megatrading Jakarta. Universitas Islam Negeri Syarif Hidayatullah. Jakarta

9. Kroemer, K.H.E. 2008. Fitting the Human. Introduction to Ergonomics. Sixth Edition. CRC Press. Taylor \& Francis Group.
10. Okananto, A. 2014. Pengaruh Pemberian Peregangan (Stretching) Terhadap Penurunan Keluhan Nyeri Pinggang Dan Nyeri Punggung Bawah (Low Back Pain) Pada Pekerja Bagian Menjahit CV.Vanilla Production Susukan Semarang. Naskah Publikasi. Program Studi Kesehatan Masyarakat. Fakultas Ilmu Kesehatan. UMS.

11. Permana, D.R. 2010. Perbedaan Nilai Kesegaran Punggung Sebelum dan Sesudah Pemberian Stretching Mc. Kesnzie Extension pada Pekerja Wanita Pengepak Jamu PT. X Semarang. Vol. 9, No. 1, April 2010, hal 18-26.

12. Setiawan, A. 2014. Model Senam Pekerja untuk Meningkatkan Produktivitas Kerja Buruh. Jurnal Media Ilmu Keolahragaan Indonesia. Volume 4. Nomor 1. Edisi Juli 2014. ISSN: 208-6802.

13. Susana, I. G. B. 2016. Rancangan Ruang Pengering Berbasis Ergonomi Menurunkan Keluhan Muskuloskeletal Perajin Ikan. Dinamika Teknik Mesin. Volume 6. No. 1 Juni 2016. Teknik Mesin F.T. Universitas Mataram.

14. Sutarna, I. N. 2011. Aplikasi Ergonomi pada Proses Pemotongan Pelat Eser Meningkatkan Kinerja Mahasiswa di Bengkel Teknologi Mekanik Politeknik Negeri Bali. Tesis. Denpasar: Universitas Udayana.

15. Waldman, S.D. 2012. Atlas of Common Pain Syndromes. Third edition. Elsevier Inc. Philadelphia.

16. Wignjosoebroto, S. 2008. Ergonomi, Studi Gerak dan Waktu. Teknik Analisa untuk Peningkatan Produktivitas Kerja. Jakarta: Guna Widya. 